\title{
Comparative Study of the Response of Membrane Electrodes Based on Calix[6]arene and Calix[8]arene Derivatives to Organic Ammonium Ions
}

\author{
Takashi Katsu, ${ }^{* \dagger}$ Nozomi OKaKI, ${ }^{*}$ Kiyoyuki Watanabe, ${ }^{* *}$ Kiyoka TaKaishi,*** and \\ Hirochika YoKosU***
}

\author{
*Faculty of Pharmaceutical Sciences, Okayama University, Okayama 700-8530, Japan \\ ** Criminal Investigation Laboratory, Okayama Prefectural Police Headquarters, \\ 1-3-2, Tonda-cho, Okayama 700-0816, Japan \\ ***Tokyo Kasei Kogyo Co., Ltd., 6-15-9, Toshima, Kita-ku, Tokyo 114-0003, Japan
}

\begin{abstract}
p-tert-Butylcalix[8]arene-octaacetic acid octaethyl ester and calix[8]arene-octaacetic acid octaethyl ester well recognized 2-phenylethylamine and phenylalanine methyl ester compared with the corresponding calix[6]arene derivatives. Moreover, the calix[8]arene derivatives, especially one having tert-butyl groups, gave better selectivity against biologically active amines having a complicated structure, such as norephedrine. We considered the interaction between calixarenes and organic ammonium ions from the viewpoint of molecular symmetries.
\end{abstract}

(Received December 13, 2002; Accepted March 3, 2003)

Calixarenes have been successfully used to construct ionselective electrodes for primary organic ammonium ions as well as alkali metal cations. ${ }^{1-4}$ The hydrophobic cavities generated by the aromatic walls of phenol residues are potentially useful for the inclusion of non-polar moieties of alkylammonium ions. ${ }^{1,2,4}$ Among various calixarene derivatives, calix[6]arenehexaacetic acid hexaethyl ester (see the structure in Fig. 1) was an excellent ionophore for making a hexylammonium-selective electrode $;^{5}$ this ionophore, named amine ionophore I, soon became commercially available from Fluka. ${ }^{6}$ Later, it was found to induce a strong response to methylammonium among primary ammonium ions. ${ }^{7,8} \quad$-tert-Butylcalix[6]arenehexaacetic acid hexaethyl ester was also found to be an ionophore for making an ethylammonium-selective electrode. ${ }^{9}$ In general, the hydrophobic cavities of calix[6]arene are potentially useful for the inclusion of linear alkyl groups of small size..$^{5,7-9}$

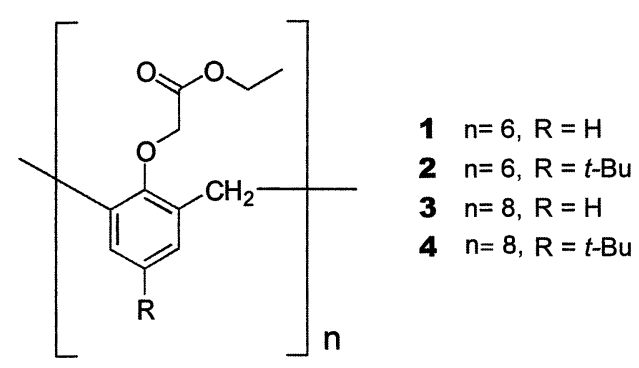

Fig. 1 Chemical structures of tested ionophores. Calix[6]arenehexaacetic acid hexaethyl ester (amine ionophore I) (1), p-tertbutylcalix[6]arene-hexaacetic acid hexaethyl ester (2), calix[8]areneoctaacetic acid octaethyl ester (3), and p-tert-butylcalix[8]areneoctaacetic acid octaethyl ester (4).

\footnotetext{
† To whom correspondence should be addressed.

E-mail: katsu@ pharm.okayama-u.ac.jp
}

As a continuation and extension of these studies, we were particularly interested in the use of calix[8]arene derivatives with larger hydrophobic cavities. Shvedene et al. ${ }^{10}$ reported that an electrode based on one of the calix[8]arene derivatives, $p$-1adamantylcalix[8]arene-octaacetic acid octaethyl ester, responded strongly to phenylalanine methyl ester as well as 2phenylethylamine, suggesting that the ability of calix[8]arene derivatives to recognize organic ammonium ions is significantly different from that of calix[6]arene derivatives. In the present study, we used the calixarene derivatives shown in Fig. 1, and systematically compared the response characteristics of calix [8] arene derivatives with those of calix[6]arene derivatives. We tested the organic amines shown in Fig. 2, in addition to various inorganic cations and simple organic ammonium ions tested previously. ${ }^{9,11}$ These calix[8] arene derivatives were also found to well recognize 2-phenylethylamine and phenylalanine methyl ester compared with the corresponding calix[6]arene derivatives. Moreover, the calix[8]arene derivatives, especially 4, gave better selectivity against biologically active amines of a complicated structure, such as norephedrine.

\section{Experimental}

Reagents

Calix[8]arene-octaacetic acid octaethyl ester, p-tertbutylcalix[8]arene-octaacetic acid octaethyl ester, and p-tertbutylcalix[6]arene-hexaacetic acid hexaethyl ester were synthesized according to similar procedures, as described previously. ${ }^{12,13}$ Other chemicals were obtained from the following sources: amine ionophore I and bis(2-ethylhexyl) sebacate were from Fluka (Buchs, Switzerland); potassium tetrakis( $p$-chlorophenyl)borate (KTpClPB) was from Dojindo Laboratories (Kumamoto, Japan); poly(vinyl chloride) (PVC) (degree of polymerization, 1020) was from Nacalai Tesque (Kyoto, Japan); 2-phenylethylamine hydrochloride and Lphenylalanine methyl ester hydrochloride were from Sigma (St. 
5<smiles>CC(N)C(O)c1ccccc1</smiles>

7

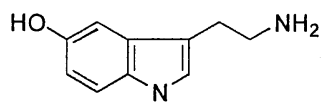

9<smiles>NCCc1ccccc1</smiles>

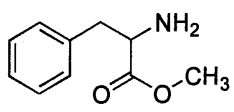

6<smiles>NCCc1ccc(O)c(O)c1</smiles>

8

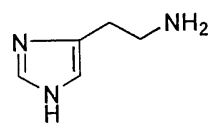

10
Fig. 2 Chemical structures of organic amines tested in this study. 2-Phenylethylamine (5), phenylalanine methyl ester (6), norephedrine (7), dopamine (8), serotonin (9), and histamine (10).

Louis, MO, USA); and D,L-norephedrine hydrochloride was from Tokyo Kasei (Tokyo, Japan). All other chemicals were of analytical reagent grade.

\section{Electrode system}

The electroactive membranes were prepared by incorporating $1 \mathrm{mg}$ of ionophore, $20 \mathrm{~mol} \%$ of KTpClPB relative to the ionophore, $60 \mu \mathrm{l}(55 \mathrm{mg})$ of bis(2-ethylhexyl) sebacate, and 30 mg of PVC.,11 The materials were dissolved in tetrahydrofuran (about $1 \mathrm{ml}$ ) and poured into a flat Petri dish $(28 \mathrm{~mm}$ in diameter). Then, the solvent was evaporated off at room temperature. The resulting membrane was excised and attached to a PVC tube $(4 \mathrm{~mm}$ o.d., $3 \mathrm{~mm}$ i.d.) with tetrahydrofuran adhesive. Each PVC tube was filled with an internal solution comprising (a) $1 \mathrm{mM}$ 2-phenylethylamine hydrochloride and 10 $\mathrm{mM} \mathrm{NaCl}$ or (b) $1 \mathrm{mM}$ D,L-norephedrine hydrochloride and 10 $\mathrm{mM} \mathrm{NaCl}$. The internal solutions (a) and (b) were, respectively, used when 2-phenylethylamine and norephedrine were examined as primary ions. The sensor membrane was conditioned overnight in the respective internal solution. The electrochemical cell arrangement was $\mathrm{Ag}, \mathrm{AgCl} /$ internal solution/sensor membrane/sample solution/1 M lithium acetate (salt bridge)/10 mM KCl/Ag,AgCl. Potential measurements were made with a voltmeter produced by a field-effect transistor operational amplifier (LF356; National Semiconductor, Sunnyvale, CA, USA; input resistance $>10^{12} \Omega$ ) connected to a recorder (R-62; Rikadenki, Tokyo Japan). The volume of the sample solution was $1 \mathrm{ml}$, because our electrode system was compact, as described previously. ${ }^{14-16}$

\section{Evaluation of the electrode performance}

The detection limit was defined as the intersection of the extrapolated linear regions of the calibration graph. ${ }^{17}$ The selectivity coefficients of the electrode, $k_{i, j}^{\text {Pot }}$, were determined by a separate solution method ${ }^{17}$ using the respective chloride salts. The concentrations were adjusted to $10 \mathrm{mM}$. In some instances, a matched potential method ${ }^{18}$ was also applied to evaluate the selectivity coefficients. In this case, we used a fixed concentration $\left(1.0 \times 10^{-5} \mathrm{M}\right)$ of 2-phenylethylamine as a background. The selectivity coefficients were calculated from the concentration of the interfering ion that induced the same amount of potential change as that induced by increasing the concentration of 2-phenylethylamine to $2.0 \times 10^{-5} \mathrm{M}$. This measurement was performed in the presence of $0.1 \mathrm{M} \mathrm{MgCl}_{2}$ to keep the ionic strength of the solution constant, and $\mathrm{MgCl}_{2}$ was chosen because the interference by magnesium was very slight. All measurements were performed at room temperature (about $\left.25^{\circ} \mathrm{C}\right)$.

\section{Results and Discussion}

We compared the potentiometric ion selectivity coefficients of electrodes based on the calix[6]arene and calix[8]arene derivatives for various organic ammonium ions and inorganic cations, choosing 2-phenylethylamine as the primary ion (Fig. 3). These were determined by a separate solution method. ${ }^{17}$ The electrode made from calix[6]arene-hexaacetic acid hexaethyl ester (amine ionophore I) (1; this number corresponds to that shown in Fig. 3) responded most strongly to 2phenylethylamine among the organic ammonium ions tested in this study. However, there was a large interference by $\mathrm{Tl}^{+}$and $\mathrm{Cs}^{+}$, in accordance with the fact that this ionophore also acts as thallium and cesium ionophores. ${ }^{11,19}$ In the case of $p$-tertbutylcalix[6]arene-hexaacetic acid hexaethyl ester (2), the response to 2-phenylethylamine decreased remarkably, indicating that the existence of bulky tert-butyl groups blocks the inclusion of phenylethylamine in the cavity of calix[6]arene. This ionophore responded strongly to organic ammonium ions of small size, such as ethylammonium, as has been previously reported. ${ }^{9}$ The electrode made from calix [8] arene derivative (3) and $p$-tert-butylcalix[8]arene derivative (4) responded most strongly to phenylethylamine among various organic ammonium ions and inorganic cations. Shvedene et al. ${ }^{10}$ reported that $p$-1-adamantylcalix[8]arene derivative responded to phenylalanine methyl ester in addition to 2phenylethylamine. This indicates that the cavity of calix[8] arene is large enough to include more bulky molecules than phenylethylamine. In accordance with this fact, both calix[8]arene derivatives with and without $p$-tert-butyl groups (3 and 4) responded to L-phenylalanine methyl ester more strongly than calix[6]arene derivatives ( $\mathbf{1}$ and $\mathbf{2}$ ), though the response was somewhat smaller than in the case of 2phenylethylamine, as shown in Fig. 3. To cross-check the values of the selectivity coefficients, we measured the selectivity coefficients against L-phenylalanine methyl ester for all of the calixarene derivatives tested using a matched potential method. The logarithmic values were -2.1 for $\mathbf{1},-1.2$ for $\mathbf{2}$, -0.6 for $\mathbf{3}$, and -0.3 for $\mathbf{4}$. These values were similar to those obtained by the separate solution method shown in Fig. 3. Such a good correlation between the selectivity coefficients measured by the separate solution method and the matched potential method has generally been observed with electrodes using calixarene derivatives..$^{9,11}$

Here, it is of interest to consider the interaction between calixarenes and organic ammonium ions from the viewpoint of their molecular symmetries. Figure 4 shows a schematic illustration of the interaction between calix[6]arene-hexaacetic acid hexaethyl ester and the primary organic ammonium ion. In this figure, we depict the conformation of the calixarene as a cone form. The molecular basis for the recognition of calix[6]arene derivatives by primary organic ammonium ions is that receptors bearing a $C_{3}$-symmetrical proton acceptor site (negatively polarized oxygen atoms of carbonyl groups) of the calix[6]arene derivatives can strongly interact with primary ammonium ions, which act as $C_{3}$-symmetrical proton donors. ${ }^{20,21}$ Furthermore, the hydrophobic cavities generated by the aromatic walls of phenol residues of the derivatives are potentially useful for the inclusion of non-polar moieties of 


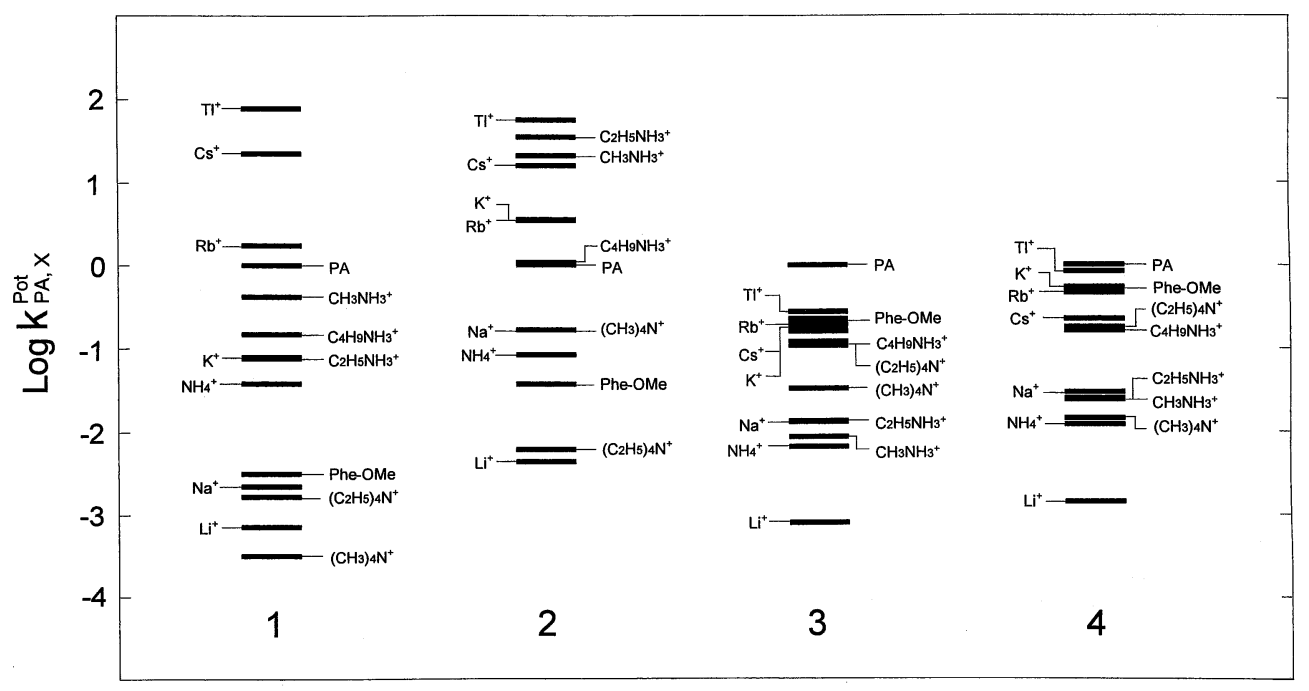

Fig. 3 Comparison of the selectivity coefficients of electrodes. Each number corresponds to the number of compounds shown in Fig. 1. Bis(2-ethylhexyl) sebacate was used as the solvent mediator. 2-Phenylethylamine was chosen as the primary ion. Abbreviations used: PA, 2-phenylethylamine; Phe-OMe, L-phenylalanine methyl ester.

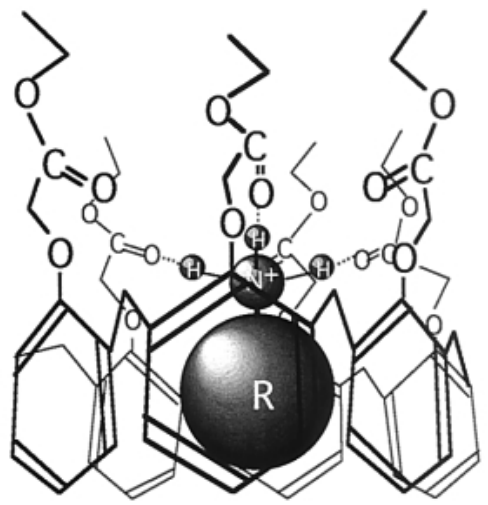

Fig. 4 Schematic illustration of the complexation geometry between calix[6]arene-hexaacetic acid hexaethyl ester and the primary organic ammonium ion.

organic ammonium ions. Thus, these derivatives were successfully used to construct electrodes responsive to specific organic ammonium ions., ${ }^{1,2,-9,21}$ However, the calix[6]arene derivatives were effective for rather small molecules, such as methylammonium and ethylammonium..$^{-9}$ In the case of bulky organic ammonium ions, the use of calixarenes having a larger cavity, such as calix[8]arene derivatives, would be effective. However, calix[8]arene derivatives, whose proton acceptor site is not $C_{3}$-symmetrical, might restrict the interaction with primary ammonium ions for a difference in symmetry. Nevertheless, we observed that the proton acceptor site of the calix[8]arene derivatives, which deviated from $C_{3}$-symmetry, was still able to interact especially with organic ammonium ions of an "unsymmetrical" structure, such as phenylalanine methyl ester. This implies that calix[8]arene derivatives were rather effective for the recognition of bulky and unsymmetrical organic ammonium ions, using a large cavity and choosing an appropriate position at the proton acceptor sites to interact with these primary ammonium ions.

Thus, we further examined the ability of these calix[8]arene derivatives to discriminate organic ammonium ions having a complicated structure. Because phenylalanine methyl ester possesses a "2-phenylethylamine skeleton", we were particularly interested in examining the response characteristics of biologically active amines having this skeleton, i.e., norephedrine, dopamine, serotonin, and histamine. The structures of these amines are shown in Fig. 2, along with 2phenylethylamine. As shown in Fig. 5, both calix[8]arene derivatives (3 and $\mathbf{4})$ responded most strongly to norephedrine among the biologically active amines, except for 2phenylethylamine, indicating that the derivatives well recognized certain biologically active amines of unsymmetrical and complex structures. The derivative $\mathbf{4}$ discriminated norephedrine better than $\mathbf{3}$, in accordance with the greater ability of $\mathbf{4}$ to recognize phenylalanine methyl ester, shown in Fig. 3. The norephedrine and phenylalanine methyl ester had well-separated hydrophilic and hydrophobic parts, which probably fitted the interaction with the derivative 4 .

Then, calibration graphs were obtained for the electrodes by measuring known amounts of D,L-norephedrine hydrochloride added to $0.1 \mathrm{M} \mathrm{MgCl}_{2}$, and plotting the concentrations against the corresponding potential readings. A high concentration of $\mathrm{MgCl}_{2}$ was added to adjust the ionic strength of the solution, ${ }^{9}$ and $\mathrm{MgCl}_{2}$ was chosen because the interference from magnesium was slight $\left(\log k_{\mathrm{NER}, \mathrm{Mg}^{2+}}^{\mathrm{Pot}}<-4\right)$. As shown in Fig. 6 , all of the ionophores tested in this study gave near-Nernstian responses to norephedrine. Table 1 summarizes the response characteristics of the electrodes. Calix[8]arene derivatives (3 and 4) showed a higher sensitivity than the corresponding calix[6]arene derivatives (1 and 2). The slope and the detection limit for 3 were $57 \mathrm{mV}$ per concentration decade and $2 \times 10^{-6}$ $\mathrm{M}$, respectively, and those for 4 were $52 \mathrm{mV}$ per concentration decade and $2 \times 10^{-6} \mathrm{M}$, respectively. The response times $(90 \%$ final signal) of both electrodes were below $10 \mathrm{~s}$ when the concentration of norephedrine hydrochloride was changed from 10 to $100 \mu \mathrm{M}$. The lifetimes of the electrodes were more than one month, similar to those of other electrodes using calixarene derivatives reported previously. ${ }^{5,10}$ The $\mathrm{pH}$ dependence $(\mathrm{pH} 2$ 12) of the electrodes using the ionophores $\mathbf{3}$ and $\mathbf{4}$ was also examined at $1 \mathrm{mM}$ D,L-norephedrine in a manner similar to that described previously. ${ }^{9}$ The electrode response was independent of the $\mathrm{pH}$ over a $\mathrm{pH}$ range of $3-8.5$. The decrease in the potential above $\mathrm{pH} 8.5$ was attributable to an increase in the 


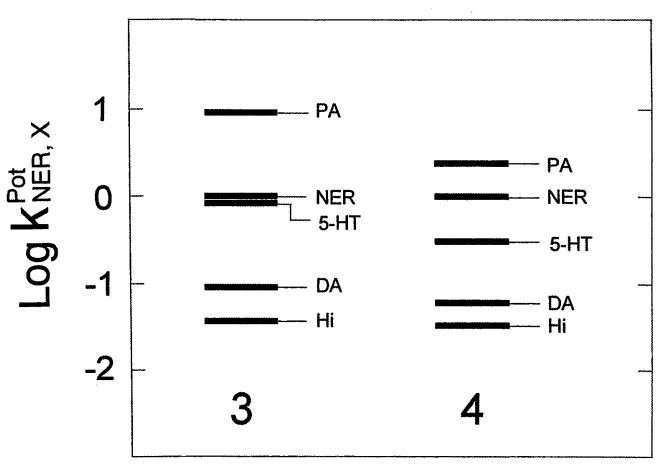

Fig. 5 Comparison of the selectivity coefficients of electrodes based on calix[8]arene-octaacetic acid octaethyl ester (3) and p-tertbutylcalix[8]arene-octaacetic acid octaethyl ester (4). Bis(2ethylhexyl) sebacate was used as the solvent mediator. D,LNorephedrine was chosen as the primary ion. Abbreviations used: PA, 2-phenylethylamine; NER, D,L-norephedrine; 5-HT, serotonin; DA, dopamine; Hi, histamine.

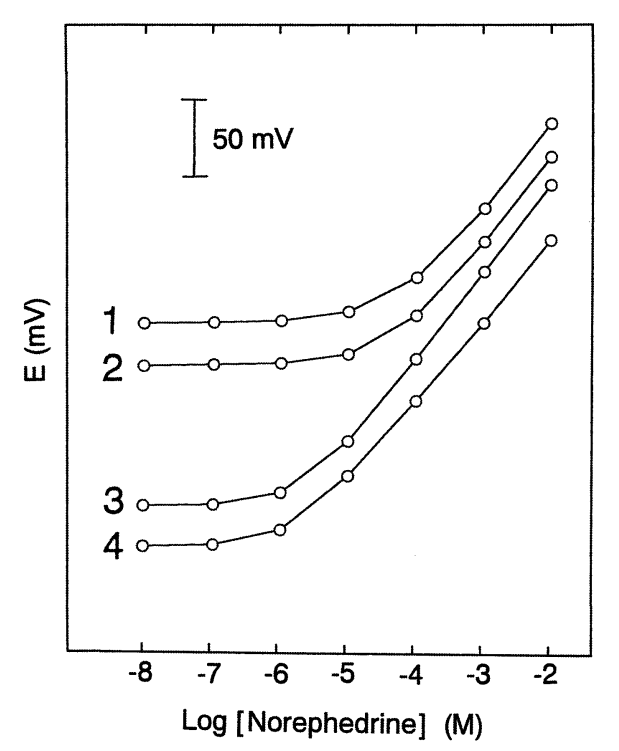

Fig. 6 Comparison of the response of electrodes to D,Lnorephedrine in $0.1 \mathrm{M} \mathrm{MgCl}$. Calix[6]arene-hexaacetic acid hexaethyl ester (amine ionophore I) (1), p-tert-butylcalix[6]arenehexaacetic acid hexaethyl ester (2), calix[8]arene-octaacetic acid octaethyl ester (3), and p-tert-butylcalix[8]arene-octaacetic acid octaethyl ester (4).

concentration of unprotonated amine, since the $\mathrm{p} K_{\mathrm{a}}$ of norephedrine has been reported to be 9.55 .22 The decrease in the potential below pH 3 may be due to the protonation of calix[8]arene derivatives in the membrane phase, resulting in a loss of the ability to complex with norephedrine. A similar observation was made with an ethylammonium electrode using ionophore $\mathbf{2}$ and a thallium electrode using ionophore 1.9,11

These results demonstrated that calix[8]arene derivatives, especially 4, can discriminate biologically active amines of a complicated structure, such as norephedrine.

\section{Acknowledgements}

This work was supported by a Grant-in-Aid for Scientific
Table 1 Comparison of the electrode performance in response to D,L-norephedrine ${ }^{\mathrm{a}}$

\begin{tabular}{ccc}
\hline Ionophore & Slope $/ \mathrm{mV}$ per decade & Detection limit $/ \mu \mathrm{M}$ \\
\hline $\mathbf{1}$ & 50 & 30 \\
$\mathbf{2}$ & 52 & 30 \\
$\mathbf{3}$ & 57 & 2 \\
$\mathbf{4}$ & 52 & 2 \\
\hline
\end{tabular}

a. Bis(2-ethylhexyl) sebacate was used as the solvent mediator. All measurements were performed in $0.1 \mathrm{M} \mathrm{MgCl}_{2}$.

Research (No. 13672254) from the Japan Society for the Promotion of Science.

\section{References}

1. P. Bühlmann, E. Pretsch, and E. Bakker, Chem. Rev., 1998, 98, 1593.

2. R. Ludwig, Fresenius J. Anal. Chem., 2000, 367, 103.

3. Y. Umezawa, P. Bühlmann, K. Umezawa, K. Tohda, and S. Amemiya, Pure Appl. Chem., 2000, 72, 1851.

4. Y. Umezawa, P. Bühlmann, K. Umezawa, and N. Hamada, Pure Appl. Chem., 2002, 74, 995.

5. W. H. Chan, K. K. Shiu, and X. H. Gu, Analyst, 1993, 118, 863.

6. Fluka Chemika Selectophore ${ }^{\circledR}$, 1996, Fluka, Buchs, Switzerland.

7. T. Katsu, D. Xu, K. Tsuji, and T. Nagamatsu, Anal. Chim. Acta, 1997, 354, 301.

8. T. Katsu, M. Akagi, T. Hiramatsu, and T. Tsuchiya, Analyst, 1998, 123, 1369.

9. T. Katsu and K. Ido, Anal. Sci., 2002, 18, 473.

10. N. V. Shvedene, M. Yu. Nemilova, V. V. Kovalev, E. A. Shokova, A. K. Rozov, and I. V. Pletnev, Sens. Actuators $B, \mathbf{1 9 9 5}, 26-27,372$.

11. T. Katsu, K. Ido, K. Takaishi, and H. Yokosu, Sens. Actuators B, 2002, 87, 331 .

12. M. A. McKervey, E. M. Seward, G. Ferguson, B. Ruhl, and S. J. Harris, J. Chem. Soc., Chem. Commun., 1985, 388.

13. F. Arnaud-Neu, E. M. Collins, M. Deasy, G. Ferguson, S. J. Harris, B. Kaitner, A. J. Lough, M. A. McKervey, E. Marques, B. L. Ruhl, M. J. Schwing-Weill, and E. M. Seward, J. Am. Chem. Soc., 1989, 111, 8681.

14. T. Katsu, H. Kobayashi, and Y. Fujita, Biochim. Biophys. Acta, 1986, 860, 608.

15. T. Katsu, K. Ido, S. Sagara, K. Tsubaki, and K. Fuji, Electroanalysis, 2003, 15, 287.

16. K. Yasuda, C. Ohmizo, and T. Katsu, J. Microbiol. Methods, 2003, 54, 111.

17. R. P. Buck and E. Lindner, Pure Appl. Chem., 1994, 66, 2527.

18. Y. Umezawa, K. Umezawa, and H. Sato, Pure Appl. Chem., 1995, 67, 507.

19. A. Cadogan, D. Diamond, M. R. Smyth, G. Svehla, M. A. McKervey, E. M. Seward, and S. J. Harris, Analyst, 1990, 115, 1207.

20. S.-K. Chang, M. J. Jang, S. Y. Han, J. H. Lee, M. H. Kang, and K. T. No, Chem. Lett., $1992,1937$.

21. K. Odashima, K. Yagi, K. Tohda, and Y. Umezawa, Anal. Chem., 1993, 65, 1074.

22. T. B. Vree, A. Th. J. M. Muskens, and J. M. van Rossum, J. Pharm. Pharmacol., 1969, 21, 774. 